\title{
Koruyucu Hizmetler Sağlık Harcamalarını Azaltabilir mi?
}

\section{Can Preventive Services Help To Reduce Health Care Expenditures?}

\section{Osman Hayran}

İstanbul Medipol Üniversitesi Tip Fakültesi Halk Sağğğı Anabilim Dalı Kavacık-Beykoz İstanbul

\author{
Yazı̧̧a Adresi / Correspondence: \\ Dr. Osman Hayran \\ İstanbul Medipol Üniversitesi Tip Fakültesi Halk Sağlığı Anabilim Dalı Kavacık-Beykoz İstanbul \\ E-mail: ohayran@gmail.com \\ Orcid \\ Osman Hayran https://orcid.org/0000-0002-9994-5033
}

Geliş Tarihi / Received : 31-10-2018 Kabul Tarihi / Accepted : 05-11-2019 Yayın Tarihi / Online Published: 27-12-2019

Hayran 0., Koruyucu hizmetler sağlı harcamalarını azaltabilir mi?,

J Biotechnol and Strategic Health Res. 2019;3(3):170-175 DOİ: bshr.640902

\begin{abstract}
Özet
Tıp ve sağlı hizmetlerindeki gelișmeler nedeniyle tüm dünyada doğumda yașam beklentisi artmaktadır. Bunun doğal sonucu olarak demografik açıdan yașlı nüfus artmakta, epidemiyolojik açıdan da hastalık türleri ve ölüm nedenleri değişmektedir. Bu gelişmelere ek olarak tüm ülkelerde sağlık harcamaları kişi başına düşen milli gelir artışından daha hızlı artmakta ve yöneticileri sağlık harcamalarını kontrol konusunda arayışlara itmektedir. Sağlık harcamalarını azaltmak veya kontrol altına almak için en sık dile getirilen çözüm önerilerinden birisi koruyucu sağlık hizmet sunumuna ağırlık verilmesidir. Bu makalede yaşlı nüfusun sayısal artışının gerçekten sağlık harcamalarında artışa yol açıp açmadığı ve koruyucu hizmet sunumunun neden sağlık harcamalarını azaltıcı değil de tam tersine arttırıcı etkisinin olduğu konuları tartışılmış̦tır.

Anahtar Yaşlılık, Koruyucu hizmetler, Sağlık harcamaları

Life expectancy at birth is increasing globally due to rapid developments in medicine and health services. As a consequence of this increase geriatric age group is growing and disease profiles are changing. Health care expenditures are also increasing rapidly parallel to these demographic and epidemiologic transformations. Increase of health care expenditures per capita is higher than the increase of GDP per capita in most countries and all decision-makers are struggling to control the increase. Focusing on preventive health services is among the most favorite solutions for controlling the health care expenditures. In this review article the influence of the increase of geriatric age group and the role of preventive health services to reduce health care expenditures are discussed.

Keywords Aged-population, Preventive healthcare, Healtcare expenditures 


\section{Giriş}

Tıpta ve sağlık hizmetleri sunumundaki gelişmeler sayesinde özellikle bulaşıcı hastalıklarla mücadelede önemli başarılar elde edilmiş, pek çok erken ölüm önlenebilmiş ve doğumda yaşam beklentisi tüm dünyada önemli şekilde yükselmiştir. Dünya Sağlık Örgütü istatistiklerine göre kadın ve erkekler için 2000 yılında ortalama olarak 66.5 yıl olan doğumda yaşam beklentisi, küresel düzeyde toplam 5.5 yıl artarak 2016 da 72.0 yıl olmuştur. Sağlıklı yaşam beklentisi de (HALE) benzer şekilde artmış ve 58.5'den 63.3’e yüksselmiştir. Her iki gösterge de kadınlarda erkeklere göre daha yüksek değere sahiptir. ${ }^{1}$

Ortaya çıkan demografik değişim doğal olarak yeni sağlık sorunlarına, hastalık profillerinde farklılaşmalara yani epidemiyolojik değişimlere yol açmaktadır. Bu demografik ve epidemiyolojik değişimler halk sağlığı açısından iki önemli ezberin tartışmaya açılmasını sağlamıştır. Bunlardan birisi "yaşlı nüfusun artışına bağlı olarak sağlık harcamalarının hızla artacağı", diğeri ise "koruyucu sağlık hizmetlerine ağırlık verilerek sağlık harcamalarının azaltılabileceği” şeklindeki ezberlerdir.

\section{Yaşlı nüfusun artışı ile sağlık}

harcamaları hizla artacak mi?

Özellikle gelişmiş ülkelerde sağlık harcamalarının artış hızı uzunca bir zamandır gayri safi milli hasıla artış hızından daha yüksek seyretmektedir ve yakın bir gelecekte sağlık sistemlerinin finansmanı konusunda yaşanacak ciddi krizlerin habercisi niteliğindedir. Sağlık harcamalarındaki artışlar teorik olarak üç nedenden kaynaklanmaktadır. Bunlar, hizmet sunulması gereken nüfustaki artışlar, aynı hizmetlerin sunumundaki kalite ve maliyetlere bağlı fiyat artışları, hizmet konusu olan hastalık ve sağlık sorunlarındaki değişimlere bağlı artışlardır. Bu üç etkenden herhangi birisi ya da birkaçının etkisi sonucu sağlık harcaması artışı olmaktadır.

Artışların kaynağının saptanması alınacak önlemler ve belirlenecek politikalar açısından önemlidir. Örneğin, eğer artışlar ağırlıklı olarak demografik değişimlerden kaynaklanıyor ise politikaların yaşlı nüfusa hizmet sunumu ve kronik hastalık yönetimi konularına yoğunlaşması gerekecektir. Eğer artışların kaynağı öncelikle kullanılan teknolojinin ve sunulan hizmet türünün niteliği ise bunların daha maliyet-etkin kullanımına odaklanmak önem taşıyacaktır. Yok eğer artışın nedeni hastalıkların, sağlık sorunlarının nitelik ve miktarındaki değişimler ise o zaman da bunların denetim altına alınması için koruyucu önlemlere ağırlık vermek ön planda olacaktır. Sağlık harcamalarında etkisi olan değişkenlerin fazlalığı ve bazı değişkenlerden kaynaklanan karıştırıcılık nedeniyle ayrıntılı analizlerin yapılması zor olduğundan genellikle kolaycı yol tercih edilmekte ve yaşlı nüfusun artışının sağlık harcamalarını artıracağı klişesi sık olarak tekrarlanmaktadır.

Yapılan çalışmalara göre bebeklik döneminde çok fazla olan sağlık harcamaları çocuklar ve gençler için azalmakta, yetişkin yaşlarda artmaya başlamakta, özellikle 50 yaşın üzerinde katlanarak artmaktadır. ${ }^{2}$ Yaşlı insanların yıllık sağlık harcamasının adolesan dönem gençlerine kıyasla 4-5 kat daha fazla olduğu hesaplanmaktadır. ${ }^{3}$

Yaşlılık döneminde de yaşın artışı ile harcamaların artışı arasında da doğrusal bir ilişki bulunmaktadır. Bazı hesaplamalara göre 85 yaş üzeri kişilerin sağlık harcaması 65-74 yaştakilerin yaklaşık üç katı, 75-84 yaş grubundakileri ise yaklaşık iki katı daha fazladır. ${ }^{4}$ Yaşam boyu sağlık harcaması yönünden kadınlarla erkekler arasında da farklılık bulunmaktadır. Yapılan bir çalışmada kadınlar için yaşam boyu sağlık harcaması erkeklerin \%34'ü kadar daha yüksek bulunmuştur. Bu farkın bir kısmı (\%40’1) kadınların erkeklerden daha uzun yaşamasına bağlı olmakla birlikte yarıdan daha fazlasının kadınların daha fazla harcamaya neden olmasına bağlı olduğu anlaşılmaktadır. ${ }^{5}$

ABD'de yapılan bir çalışmada özellikle hastane ve hekim kaynaklı akut bakım harcamalarının ölüm yaşının artması ile birlikte azalma gösterdiği, uzun dönem bakım harcamalarının ise tam tersine hızlı bir artış gösterdiği görül- 
müştür.

İsviçre'de yapılan bir çalışmada toplumun yaşlanmasının yıllık sağlık harcamalarında sadece \% 0.5’lik bir artışa neden olduğu saptanmıştır. ${ }^{7}$ Kanada'da yapılan bir çalışmada ise sağlık harcamalarındaki artışta, tıbbi teknolojilerdeki değişim ve kişi başına düşen gelir artışının yaşlı nüfus artışından daha önemli rolü olduğu anlaşılmıştır. ${ }^{8}$

Avusturalya'da yapılan bir çalışmada yaşlı nüfustaki harcama artışının ağırlıklı olarak sunulan hizmetin kalitesi ve miktarı ile yani hizmetlerin sunum cephesi ile ilişkili olduğu, yaşlı nüfus artışının veya hastalık türlerindeki değişimin rolünün daha geri planda olduğu sonucuna varılmıştır. ${ }^{9}$

$\mathrm{Bu}$ sonuçlardan da anlaşılacağı gibi yapılan tüm araştırmalar doğumda yaşam beklentisinin artışı ile birlikte sağlık harcamalarının arttığını göstermekle birlikte, bu artışın toplumdaki yaşlı sayısının artmasından mı, sunulan hizmetlerin niteliğinin değişmesinden mi, yoksa yapılan harcamaların miktarından mı kaynakladığı konusu tartışmalıdır. Ortaya çıkan karmaşık sonuçlar nedeniyle yaşlı nüfus artışının sağlık harcamalarını arttıracağı tezine "Kandırmaca Teorisi" adı verilmiştir. Kandırmaca teorisine göre harcamaların artışının nedeni gerçekte "ölüme yakınlık" ile ilişkilidir. ${ }^{10}$ Yani harcama artışı aslında uzamış yaşam yıllarından değil, ölümün hemen öncesinde gerçekleşen artışlardan kaynaklanmaktadır. Başka bir deyişle, harcamalardaki artışlar hastalıklardaki ve kullanılan teknolojilerdeki değișimlerin yanı sıra, ama bunlardan daha önemli olarak "ölüme yakınlık” sırasında oluşmaktadır. Bu durumu açıklığa kavuşturmak amacıyla yapılan çeşitli çalışmalarda mortalite nedenli harcamalar ile morbiditeye bağlı harcamalar birbirinden ayrılarak incelenmiş ve benzer sonuçlar elde edilmiştir. ${ }^{11,12}$ Yakın zamanda bu çelişkileri aydınlatmak amacıyla yapılan kapsamlı bir çalışmada hem doğum kohortları hem de benzer yaş grupları arasında karşılaştırmalı analizler yapılmış ve yaşlı nüfustaki sağlık harcama artışını etkileyen en önemli değişkenin “ölüme yakınlık” olduğu sonucuna varılmıştır. ${ }^{13}$

Özet olarak yaşlı nüfusun artışı ile ortaya çıkan sağlık harcaması artışının öncelikle ölüme yakınlıkla ilişkili olduğu anlaşılmaktadır. Başka bir deyişle, sağlıklı geçirilen yaşlılık döneminde sağlık harcamaları artmamakta, sadece ölüme yakınlık anında artış göstermektedir ki bu her yaş grubu için geçerli olan yaşam süresinden bağımsız bir durumdur. ${ }^{14}$

$\mathrm{Bu}$ yaklaşım dikkate alındığında, ileri yaşlarda ortaya çıkan ve önemli bir hastalık yükü oluşturan kronik/bulaşıcı olmayan hastalıkların ötelenmesi ve ölüm yaşına yakın bir döneme sıkıştırılması halinde sağlık harcamalarının azaltılmasının mümkün olabileceği görünmektedir. Bu sayede hem yaşlılıkta geçirilecek sağlıklı yaşam yıllarının sayısı artacak hem de sağlık harcamaları azaltılabilecektir. Bunu başarmak için de koruyucu ve geliştirici sağlık hizmet sunumuna ağırlık verilmesi gerekmektedir. "Morbidite S1kıştırma Hipotezi” adı verilen ve 1980'de oluşturulan bu yaklaşımın geçerliliğine ilişkin farklı görüşler olsa da halen yaygın olarak kabul gören bir hipotezdir ${ }^{15,16,17,18,19}$

\section{Koruyucu sağlık hizmetleri sayesinde sağlık harcamaları azaltılabilir mi?}

Kişi başına sağlık harcamasının çok yüksek olduğu ABD'de sağlık harcamalarının nasıl kontrol altına alınabileceği konusu en azından son 5 seçim döneminde başkan adaylarının öncelikli konuları arasında yer almıştır. Özellikle 2008 yılındaki seçimlerde hem Demokrat Parti hem de Cumhuriyetçi Parti adaylarının sağlık harcamalarındaki artışı kontrol altına almak amacıyla koruyucu sağlık hizmetlerine ağırlık vereceklerini vurgulamaları, "koruyucu sağlık hizmetleri sunumu sayesinde sağlık harcamalarındaki artış azaltılabilir mi” konusundaki eski tartışmayı yeniden gündeme getirmiştir. ${ }^{20,21}$

Koruyucu sağlık hizmetleri sunumu sayesinde sağlık harcamalarının artışı önlenebilir mi ya da harcamaların kontrolü sağlanabilir mi sorularına uzman olmayan kişiler 
tarafından bir çırpıda verilebilecek yanıt "tabii ki evet" olacaktır. Ancak, konuya bilimsel yöntemlerle yaklaşıldığında durumun hiç de öyle olmadığı, koruyucu sağlık hizmetlerinin bazı hallerde sağlık harcamalarını azaltmak bir yana ciddi artışlara bile neden olabildiği görülmektedir. ${ }^{22}$

İnsanların hastalanmasını önlemek amacını güden koruyucu sağlık hizmetlerinin kaliteli ve uzun yaşam için gerekli olduğuna kimsenin itirazı yoktur. Ancak, koruyucu sağlık hizmetleri sayesinde sağlık harcamalarının azalacağ1 yönündeki ifadeler tartışmalıdır ve 1986 yılında yazılan bir kitabın konusu olan bu tartışmaların hayli uzun bir geçmişi vardır. ${ }^{23}$ Özellikle çocukluk döneminde sunulan koruyucu sağlık hizmetlerinin tedaviden daha ucuz olduğu ve yaşam süresine, kalitesine çok katkı sağladığı doğrudur. Ancak, bu sayede uzayan yaşam süresi sonucunda yaşlı nüfus artmakta ve bu nüfusun sağlık harcamaları gündeme gelmektedir. Bu noktada yaşlılık dönemindeki koruyucu sağlık hizmetlerinin sağlık harcamalarını arttırıp artırmayacağı sorusu önem kazanmaktadır.

Aslında koruyucu sağlık hizmetleri ile kastedilenler çok çeşitlidir ve bunlara hangi açıdan bakıldığ Koruyucu sağlık hizmetlerinin bir kısmı gereğinden fazla tanı konulmasına neden olarak pek çok kişinin gereksiz yere ilaç kullanmasına ya da müdahale görmesine neden olabilmektedir. Üstelik bazı koruyucu önlemlerin gerçekte ne kadar koruyucu olduğu konusu tartışmalı olup, bazılarının da örneğin hormon replasman terapisinde olduğu gibi yeni sorunlara (meme kanserine) yol açması mümkün olabilmektedir.

Çok basit bir sınıflama ile koruyucu sağlık hizmetler primer, sekonder ve tersiyer koruma şeklinde üçe ayrılmaktadır. Primer koruma, hastalık etkeni ile karşılaşmadan önce verilen sağlık eğitimi, bağışıklama gibi hizmetleri; sekonder koruma, hastalıkların erken dönemde saptanması amacıyla yapılan kanser ve bulaşıcı hastalık taramaları gibi erken tanı hizmetlerini; tersiyer koruma ise, hastalıklar ortaya çıktıktan sonra etkilerinden korunma amacıyla verilen tıbbi ve sosyal rehabilitasyon hizmetlerini kapsamaktadır. Bunların dışında sağlıklı kişilerin yaşam kalitesini ve iyilik halini arttırma amaçlı, sigara-alkol bırakma danışmanlığı, fiziksel aktivite, dengeli ve sağlıklı beslenme gibi riskleri azaltıcı, "sağlığı geliştirici hizmetler" de bazı yazarlar tarafından koruyucu hizmet grubuna sokulmaktadır. $\mathrm{Bu}$ hizmetlerin bir kısmı toplum içerisinde, günlük yaşam aktiviteleri sırasında sunulabilir iken bir kısmı hastane ortamında, klinik koşullarda sunulmaktadır.

Koruyucu hizmetin türü ve sunulduğu yer ne olursa olsun maliyet-azaltma, maliyet-etkinlik ve maliyet-fayda analizleri yapıldıktan sonra sunulması harcama kontrolü açısından özellikle önem taşımaktadır. Hizmetlerin değerlendirilmesinde kişinin kazanacağı QALY cinsinden bir yılın (QALY-kaliteye ayarlanmış yaşam yılı) kaça mal olduğunun hesaplanması önemlidir. Yaşlılık dönemi ile ilgili çalışmalarda etkisi incelenen koruyucu hizmetler genellikle kronik hastalıklara yönelik olarak hastane-klinik koşullarında sunulan koruyucu ve/ya geliştirici sağlık hizmetleridir. Öte yandan erken tanı amacıyla hastane ortamında sunulan pek çok sekonder koruma yönteminin maliyet-etkin olsalar bile maliyet-azaltıcı etkilerinin bulunmadığı bilinmektedir. ${ }^{24}$

Maliyet-azaltıcı ve maliyet-etkin kavramları çoğu kez birbirinin yerine kullanılan ama birbirinden farklı anlamlar taşıyan kavramlardır. Çocukluk aşıları gibi sağlık harcamalarında belirgin şekilde azalma sağlayan uygulamalar maliyet-azaltıcı hizmetler olarak nitelendirilir. Eğer sunulan bir hizmetin sonucunda sağlanan yararlar yapılan harcamalara kıyasla çok fazla ise bu durumda da maliyet-etkinlikten söz edilir. Koruyucu hizmetleri ekonomik açıdan değerlendirirken bu iki kavrama göre incelemek ve "artırımlı maliyet-etkinlik oranı" hesabı yapmak gerekir. Artırımlı maliyet-etkinlik oranı, dolar cinsinden artırımlı maliyetlerin, QALY cinsinden elde edilen artırımlı faydaya bölünmesi ile bulunur. Farklı görüşte olan sağlık ekono- 
mistleri olsa da genel olarak kazanılan her QALY için 50100 bin ABD dolarından daha az bir maliyet hesaplanması iyi bir oran anlamına gelir.

Cohen ve Neumann tarafindan hazırlanan kapsamlı bir raporda, ABD'de klinik ve hastanelerde yaygın olarak sunulan çeşitli primer ve sekonder koruyucu sağlık hizmetlerinin ekonomik değerlendirilmesinin yayınlandığ 1500 'den fazla makale incelenmiş ve yaygın olarak kullanılmakta olan koruyucu hizmetlerin ekonomik değerlendirilmesi yapılmıştır. Değerlendirme sonucunda "artırımlı maliyet-etkinlik oranı" yönünden sadece iki tür hizmetin maliyet-azaltıcı olduğu görülmüştür. Bunlar, çocukluk dönemi bağışıklama hizmetleri ile yetişkinlerde düşük doz aspirin danışmanlığ 1 hizmetleridir. ${ }^{25}$

Özellikle klinik, hastane ortamında sunulan pek çok koruyucu hizmetin sağlık harcamalarını azaltmak bir yana gereksiz harcamalara da neden olduğu anlaşılmaktadır. Ancak, bu sonuçlara bakarak koruyucu hizmetleri geri plana itmek doğru değildir. Konuya bu şekilde yaklaşıldığında tedavi amaçlı pek çok uygulamanın da gereksiz harcamalara neden olması söz konusudur.

Koruyucu hizmet karşıtı bir söyleme göre "herkes er ya da geç öleceğine göre yaşamı uzatarak insanı süründürecek hastalıklarla karşı karşıya bırakmanın anlamı yoktur”. Bu yaklaşım da doğru değildir. Çünkü, koruyucu sağlık hizmetinin anlamı bir hastalığın yerine başka bir hastalığın konulması, yani, bulaşıcı hastalıklar yerine bulaşıcı olmayan hastalıkların, ya da metabolik hastalıklar yerine dejeneratif hastalıkların konulması demek değildir. Amaç, hastalıklı ve başkalarına bağımlı geçirilen yaşam süresinin kısaltılması, sağlıklı yaşam süresinin uzatılması ve yaşam kalitesinin arttırılmasıdır. ${ }^{26,27}$

Özet olarak koruyucu sağlık hizmetlerinin sağlık harcamalarını azaltmada rolü olup olmadığı konusunda yapılan pek çok çalışmanın sonucu bilinen ezberin tam tersini göstermektedir. Koruyucu hizmetlere ağırlık vermek sağ- lık harcamalarını kısa vadede azaltıcı bir etki göstermekle birlikte yaşam beklentisine olan katkısı nedeniyle uzun vadede daha fazla sağlık harcamasına yol açmaktadır. Ancak, koruyucu sağlık hizmetleri sayesinde insanlar daha sağlıklı yaşamakta, yaşam kaliteleri daha iyi olmakta ve bunun maliyeti de düşük olmaktadır. Bu nedenle, toplum düzeyinde yaygın bir biçimde koruyucu sağlık hizmeti sunumuna harcamaları azaltma amacıyla değil toplumun daha sağlıklı olması amacıyla ağırlık verilmelidir. Bu noktada iyi olan şeylerin pahalı olduğu unutulmamalıdır.

$\mathrm{Bu}$ tür değerlendirmeler sağlık politikalarını oluştururken, incelerken ve öncelikleri saptarken gerekli olmakla birlikte, sağlık söz konusu olduğunda verilen hizmetlerin maliyetinin ne olduğunun bir önemi olmayacağı akılda tutulmalıdır.

Öte yandan, sağlık harcamalarını inceleyen ve azaltma yollarını arayan çalışmaların çoğunluğunun hizmetlerin arz yönüne odaklandığı dikkati çekmektedir. Oysa talep yönüne odaklanmak belki de daha yararlı olacaktır. Yani, bireylerin kendi sağlık sorunları ve hastalık riskleri konusunda sorumluluk üstlenmeleri, kronik hastalıkları için geliştirecekleri özyönetim becerileri ve sağlıklarını koruma konusundaki öz-yeterlilik algıları gibi hizmet talebini kontrol amaçlı eylemlere odaklanmak harcamaları en az $\% 20$ oranında ve daha etkili bir şekilde azaltabilecektir. ${ }^{28}$ Bu sonuçlar sağlığın geliştirilmesi ve sağlık eğitimi programlarının önem ve gerekliliğini bir kez daha ortaya koymaktadır. 
Journal of BSHR 2019;3(3):170-175

HAYRAN. Koruyucu Hizmetler Ve Sağlık Harcamaları

\section{Kaynaklar}

1. World health statistics overview 2019: monitoring health for the SDGs, sustainable development goals. Geneva: World Health Organization; 2019 (WHO/DAD/2019.1). Licence: CC BY-NC-SA 3.0 IGO. https://apps.who.int/iris/bitstream/handle/10665/311696/WHODAD-2019.1-eng.pdf?ua=1 erişim:27.Ekim.2019)

2. Meerding W J, Bonneux L, Polder JJ, Koopmanschap MA, van der Maas PJ. 'Demographic and Epidemiological Determinants of Healthcare Costs in Netherlands: Cost of Illness Study.' British Medical Journal 1998;317 (7151):111-5.

3. Bradford DF, Max DA. Implicit Budget Deficits: The Case of a Mandated Shift to Community-Rated Health Insurance. NBER working paper no. 5514. Cambridge, MA: National Bureau of Economic Research, 1996

4. Fuchs V. Provide, Provide: The Economics of Aging. NBER working paper no. 6642. Cambridge, MA: National Bureau of Economic Research, 1998.

5. Alemayehu B, Warner KE. The Lifetime Distribution of Health Care Costs. Health Serv Res. 2004; 39(3): 627-642. doi: 10.1111/j.1475-6773.2004.00248.x

6. Spillman BC, Lubitz J. The effect of longevity on spending for acute and long-term care. $N$ Engl J Med 2000;342:1409-15.

7. Breyer F, Costa-Font J, Felder S. Ageing, Health, and Health Care. Oxford Review of Economic Policy 2010;26(4):674-690.

8. Rossen B, Faroque A. Diagnosing the Causes of Rising Health-Care Expenditure in Canada: Does Baumol's Cost Disease Loom Large? American Journal of Health Economics 2016;2:184-212.

9. Harris A, Sharma A. Estimating the future health and aged care expenditure in Australia with changes in morbidity. PLoS ONE 2018;13(8):e0201697.

10. Zweifel P, Felder S, Meiers M. Ageing of population and health care expenditure: $a$ red herring? Health Econ. 1999;8(6):485-496.

11. Colombier C, Weber W. Projecting health-care expenditure for Switzerland: further evidence against the 'red-herring' hypothesis. Int J Health Plann Manag. 2011;26(3):246-63.

12. von Wyl V, Beck K. Risk adjustment in aging societies. Heal Econ Rev. 2014;4(1):7.

13. von Wyl V. Proximity to death and health care expenditure increase revisited: A 15-year panel analysis of elderly persons. Heal Econ Rev. 2019;9. https://doi.org/10.1186/s13561019-0224- $z$

14. Yang Z, Norton EC, Stearns SC. Longevity and Health Care Expenditures: The Real Reasons Older People Spend More. Journal of Gerontology 2003; 58B(1): S2-S10.

15. Fries JF. Aging, Natural Death, and the Compression of Morbidity. New England Journal of Medicine 1980;303(3): 130-135.
16. Fries JF. Compression of Morbidity, 1993: Life Span, Disability, and Health Care Costs. Facts and Research in Gerontology 1993; 7: 183-190.

17. Fries JF, Bruce B, Chakravarty E. Compression of Morbidity 1980-2011: A Focused Review of Paradigms and Progress. J Aging Res. 2011; 2011: 261702. doi:10.4061/2011/261702.

18. Walter S, Beltran-Sanchez H, Regidor E, Gomez-Martin C, Del-Barrio JL, Gil-de-Miguel A, Subramanian SV, Gil-Prieto R. No evidence of morbidity compression in Spain: a time series study based on national hospitalization records. Int J Public Health 2016;61:729-738. doi:10.1007/s00038-016-0829-5.

19. Geyer S. Morbidity compression: a promising and well-established concept? Int J Public Health 2016;61:727-728. doi:10.1007/s00038-016-0853-5

20. Brown D. "In the balance: some candidates disagree, but studies show it's often cheaper to let people get sick."Washington Post, p. HE01, April 8, 2008. (http://www.washingtonpost.com/ wpdyn/content/article/2008/04/04/AR2008040403803_pf.html. Erișim:28 Ekim.2019)

21. Welch HG. "Campaign myth: prevention as cure-all." New York Times, October 6, 2008 (http://www.nytimes.com/2008/10/07/health/views/07essa.html? $r=1$ bei=5070 bemc=etal ‘refeslogin. Erişim:28.Ekim.2019)

22. Welch HG. Cohen JT, Neumann PJ, Weinstein MC. "Does Preventive Care Save Money? Health Economics and the Presidential Candidates," New England Journal of Medicine 2008;358(7): 661-663.

23. Russell LB. Is Prevention Better than Cure? Washington, DC: Brookings Institution, 1986.

24. Goetzel RZ. Do Prevention Or Treatment Services Save Money? The Wrong Debate. Health Affairs 2009;28(1): 37-41.

25. Cohen JT, Neumann PJ. The cost savings and cost-effectiveness of clinical preventive care. Center for the Evaluation of Value and Risk in Health, Institute for Clinical Research and Health Policy Studies, Tufts Medical Center. Research Synthesis Report No. 18. 2009. (https://www.rwif.org/en/library/research/2009/09/cost-savings-and-cost-effectiveness-of-clinical-preventive-care.html erişim:26.Ekim.2019)

26. Fries JF. The Compression of Morbidity, 1983. Milbank Quarterly, 2005;83(4): 801-823.

27. Goetzel RZ, Reynolds K, Breslow L, Roper WL, Shechter D, Stapleton DC, Lapin PJ, Mc Ginnis JM. Health Promotion in Later Life: It's Never Too Late. American Journal of Health Promotion 2007;21(4): 1-5.

28. Fries JF, Koop CE, Sokolov J, Beadle CE, Wright D. Beyond Health Promotion: Reducing Need And Demand For Medical Care. Health Affairs, 1998;17(2):70-84 